\title{
BACIA HIDROGRÁFICA DO RIO NEGRO-RS: CONHECER PARA GERENCIAR
}

\author{
RIO NEGRO-RS WATERSHED: THE \\ IMPORTANCE OF KNOWLEDGE \\ FOR MANAGEMENT
}

RESUMO

Este artigo apresenta o projeto de extensão universitária intitulado "Bacia hidrográfica do Rio Negro: conhecer para gerenciar", seus principais aspectos e os resultados alcançados até o momento. 0 projeto tem como objetivo principal promover ações que resultem em conhecimentossobre aspectos físicos, sociais e ambientais da bacia hidrográfica do Rio Negro-RS. A metodologia utilizada para o desenvolvimento desse projeto constitui-se de: a) estudo do problema; b) definição de ações de extensão;c) planejamento das ações; d) realização das ações planejadas e f) avaliação das ações realizadas. Após três anos de execução desse projeto, é possível afirmar que tem contribuído para a conscientização da população que habita a bacia hidrográfica do Rio Negro a respeito de sua importância no contexto local e internacional etambém sobre a preservação dos recursos hídricos localizados no interior da bacia hidrográfica.

Palavras-chave: Rio Negro-RS; Bacia Hidrográfica; Meio Ambiente; Extensão Universitária.

\section{ABSTRACT}

This paper presents the University Outreach Project "Negro River watershed: the importance of knowledge for management", its main aspects and the results achieved so far. The project has been developed since the end of 2012, and aims to promote actions that result in greater knowledge about the physical, social and environmental aspects about the Negro River watershed. The method used for the development of the project include: a) the study of the problem; b) the definition of the outreach actions; c) planning the actions; d) implementing the actions; and f) evaluating the actions taken. After three years of the project, it is possible to say that it has been contributing to raise the awareness of the population that lives in the Negro River Watershed about its importance for the local and international context, as well as about the preservation of water resources located within the watershed.

Keywords: Rio Negro River- RS; Watershed; Environment; Outreach University Project.

\footnotetext{
* Aluna de Graduação da Universidade Federal do Pampa (UNIPAMPA), RS - Brasil. E-mail: viviantabranco@gmail.com
}

** Professor da Universidade Federal do Pampa (UNIPAMPA), RS - Brasil. E-mail: alexandro.schafer@unipampa.edu.br 


\section{Introduçáo}

A água está intrinsecamente ligada ao desenvolvimento de todas as sociedades e culturas. Entretanto, esse desenvolvimento impốe considerável pressão nos recursos hídricos - agricultura, energia e indústria têm impactos no uso e governança da água (UNESCO, 2015). De acordo com a Unesco (2003), todos os sinais sugerem que a crise relacionada à água que o planeta vem enfrentando vem se agravando e continuará piorando no decorrer dos próximos anos, a menos que açôes corretivas sejam realizadas. Nesse cenário, proporcionar suprimento de água adequado, tanto quantitativamente quanto qualitativamente é, sem dúvida, um dos maiores desafios para o futuro.

No Brasil, a Lei federal n. ${ }^{\circ}$ 9.433, do dia 08 de janeiro de 1997, instituiu a Política Nacional de Recursos Hídricos (PNRH) e criou o Sistema Nacional de Gerenciamento de Recursos Hídricos, com o objetivo de assegurar à atual e às futuras geraçôes água em qualidade e disponibilidade suficientes através da utilização racional e integrada, da prevenção e da defesa dos recursos hídricos contra eventos hidrológicos críticos. A bacia hidrográfica passou a ser a unidade territorial de gestão dos recursos hídricos e a água a ser considerada bem de domínio público, cuja gestão deve ser descentralizada e participativa. De acordo com IPH-HWRP (2008), a avaliação de recursos hídricos com base na bacia hidrográfica é, atualmente, reconhecida como a abordagem mais sustentável para tratar questões relacionadas aos recursos hídricos.

No caso da bacia hidrográfica do rio Negro, localizada no estado do Rio Grande do Sul, o gerenciamento integrado sustentável dos recursos hídricos coloca-se como um desafio, já que, segundo ANA (2015), o Rio Negro está incluído entre os 16\% dos rios federais com trechos críticos, apresentando criticidade tanto qualitativa como quantitativa.

A bacia hidrográfica do rio Negro-RS pertence à regiáo hidrográfica do Uruguai econtempla uma área de aproximadamente $3.000 \mathrm{~km}^{2}$.De acordo com DAEB (2007), os principais problemas encontrados na bacia em território brasileiro estáo relacionados: ao déficit hídrico; aos efluentes industriais e domésticos das áreas urbanas; aos depósitos de resíduos; à extração de materiais nas margens dos cursos d'água e à ocupação de áreas de preservação permanentes por atividades rurais.

Segundo Ravanello e Pante (2013), a bacia do Rio Negro-RS apresenta elevada demanda hídrica para irrigação, sendo impossível atender a todos os usuários irrigantes no período de safra do arroz (de outubro a março)). De acordo com DAEB (2007), ocorrem falhas no atendimento das demandas primárias. Além disso, o atendimento ao abastecimento público também apresenta problemas, ocasionado por questóes relacionadas às características de recarga da bacia hidrográfica, que culminam em severos processos de racionamento de água na área urbana de Bagé. O déficit hídrico é agravado significantemente nos períodos de estiagem, que são recorrentes na região. Segundo dados da defesa civil (2010) e SEMA (2012), o maior número de pessoas afetadas pelas estiagens no período de 2009/2010, no Rio Grande do Sul, foi registrado nas bacias hidrográficas dos rios Camaquã e Negro. As estiagens registradas nos anos 2000 mostram que os usos da água na bacia e também na regiáo operam com um alto índice de risco, comprovado pelo frequente decreto de situaçáo de emergência por parte dos municípios abrangidos pela bacia, destacando-se Bagé (DAEB, 2007).

Além do déficit hídrico, outro problema que tende a se agravar nos próximos anos é a ocorrência de enchentes. De acordo com a Secretaria Nacional de Defesa Civil (2010) e SEMA (2012), as bacias hidrográficas do Rio Grande do Sul mais afetadas por alagamentos foram as bacias dos rios Santa Maria, Ibicuí, Piratinim, Negro, Pardo, Camaquã e a Mirim-São Gonçalo. Na bacia do rio Negro, recentemente, foram registradas enchentes na área urbana dos municípios de Bagé e de Hulha Negra.

Cabe ressaltaros problemas enfrentados pelo Comitê de Gerenciamento da Bacia Hidrográfica do Rio Negro-RS (CBRN), criado pelo Decreto Estadual no 45.531, de 05 de março de 2008 (RIO 
GRANDE DO SUL, 2008). Entre as dificuldades do comitê estáo a ausência de recursos financeiros, diagnóstico da bacia realizado com base em dados limitados, falta de mobilização - reuniōes com número ínfimo de participantes, desconhecimento da bacia hidrográfica e da PNRH por parte da sociedade e dos integrantes do comitê, além da falta de identidade da comunidade com os rios da região.

Levando em consideração os argumentos apresentados, verifica-se que existem sérios problemas ambientais na bacia hidrográfica do Rio Negro-RS que podem ser tratados em um contexto de gerenciamento integrado dos recursos naturais. Entretanto, para que isso seja possível, é fundamental que a comunidade residente na bacia hidrográfica possua conhecimentos sobre o lugar onde vive,suas características e problemas existentes. Dessa maneira, a implantaçáo desse tipo de gerenciamento pode ser facilitada.

\section{Material e Métodos}

\section{Área de estudo}

A bacia hidrográfica do Rio Negro em território brasileiro (bacia do Rio NegroRS) constitui-se na unidade hidrográfica U-80, conforme divisão do Sistema Estadual de Recursos Hídricos do Rio Grande do Sul (SERH-RS), abrangendo aproximadamente $3.007 \mathrm{~km}^{2}$ (SEMA, 2006). A bacia se desenvolve no sentido nordeste-sudoeste até a fronteira com o território uruguaio, abrangendo parcialmente os municípios de Aceguá, Bagé, Candiota, Dom Pedrito e Hulha Negra. Na figura 01, apresenta-se a localização da bacia hidrográfica do Rio Negro nos municípios.

\section{Figura 1: Localizaçáo da bacia hidrográfica do Rio Negro-RS nos municípios}

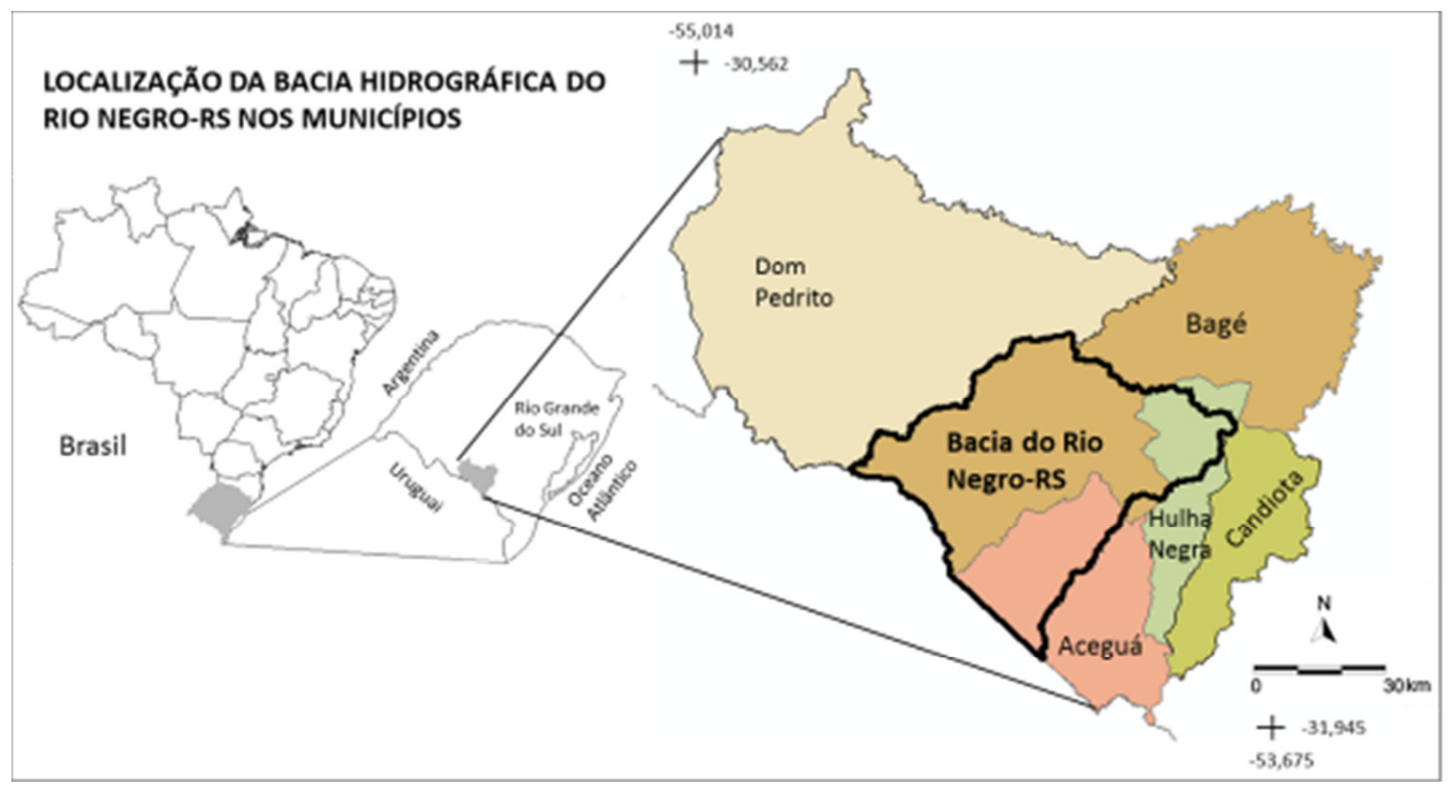

\section{Material}

Para o desenvolvimento das atividades previstas no projeto de extensão universitária, foram utilizados os seguintes materiais: a) Computadores desktop; notebooks dual core, com 4Gb de RAM e 500 GB de HD; b) Par de aparelhos Global NavigationSattelite 
System (GNSS) L1/L2, marca Topcon, modelo Hiper Lite+; c) Par de radiocomunicadores; d) Impressora Epson L1800; e) Programas computacionais:gvSIG (versão 1.11), ArcMap (versão 10.3), ENVI (versão 5.0), Draft Sight (versão 2015) e pacote Microsoft Office; f) Sistema Gerenciador de Banco de Dados PostgreSQL, com sua extensão espacial PostGIS;g) Sistema Web i3geo; h) Google Earth (Google, 2015); i) Limites das bacias hidrográficas do Rio Grande do Sul (SEMA, 2015); j) Página de download de dados geográficos do Ministério do Meio Ambiente (MMA), disponível em http://mapas.mma. gov.br/i3geo/datadownload.htm; k) Base cartográfica vetorial contínua do Rio Grande do Sul - Escala 1:50.000. (Hasenack e Weber, 2010); 1) Arquivos digitais do Sistema de Informaçôes Hidrológicas HidroWeb (ANA, 2015).

As atividades de pesquisa e de desenvolvimento do material de divulgaçáo foram realizadas no Laboratório de Modelagem, Simulaçáo Computacional e Geoprocessamento (LMSC-Geo) da Unipampa e na Escola Estadual de Ensino Médio Dr. Carlos Kluwe (E. E. E. M. Carlos Kluwe).

\section{Método}

A primeira etapa do desenvolvimento do projeto foi a realizaçáo de estudosobre a bacia hidrográfica do Rio Negro-RS e das questóes relacionadas aos recursos hídricos nos municípios que estão em sua área de abrangência. Logo após, foram definidas açóes relacionadas às atividades de pesquisa e/ou extensáo universitária que poderiam contribuir para minimizar os solucionar problemas identificados na etapa anterior. $\mathrm{O}$ próximo passo foi a identificaçáo de quais açóes poderiam ser realizadas com os recursos humanos, financeiros e infraestrutura disponíveis. Em seguida, as açóes foram planejadas e executadas, realizando-se ajustes e/ou adaptaçóes com relaçáo ao planejamento prévio, quando necessário. Por fim, realizou-se a avaliação de cada ação executada ou não.

As açôes que envolvem o contato direto com o público, como as palestras, foram avaliadas pelo próprio público por meio de questionários e pela equipe de execuçáo da ação de maneira subjetiva, levando em consideraçáo o nível de participação do público e o teor das discussóes que ocorreram após a ação. As açôes que resultavam em produtos específicos, como textos, banners, mapas, etc., foram avaliadas subjetivamente, com base na percepção da equipe de projeto e/ou por profissionais que atuam em áreas correlatas ao teor do material desenvolvido. As atividades de apoio técnico ao comitê foram avaliadas, subjetivamente, com base na percepção da equipe de projeto com relação ao aprendizado dos membros do comitê sobre a PNRHe sobre os aspectos físicos e ambientais da área de abrangência da bacia hidrográfica.

Para fins de organização e apresentação dos resultados, optou-se por separar as açóes desenvolvidas em três tópicos: a) Atividades de divulgação sobre a bacia hidrográfica do Rio Negro-RS; b) Apoio técnico ao comitê de gerenciamento da bacia hidrográfica do Rio Negro-RS; c) Atividades no Colégio Estadual de Ensino Médio Dr. Carlos Kluwe.

O público alvo das atividades de divulgação da bacia hidrográfica do Rio NegroRS é a população que vive na bacia, aproximadamente 122.000 pessoas, (IBGE, 2010). O projeto está inserido no programa institucional da Universidade Federal do Pampa (UNIPAMPA), denominado "Bacias do pampa", que visa articular a participação 
da universidade nos comitês de gerenciamento de bacia hidrográfica da região onde a UNIPAMPA foi implantada.

O publico alvo das atividades relacionadas ao apoio técnico ao CBRN é o próprio CBRN e os seus integrantes, aproximadamente 20 profissionais de órgáos públicos e privados.

O público alvo das atividades no Colégio Estadual de Ensino Médio Dr. Carlos Kluwe (C. E. E. M. Dr. Carlos Kluwe) consistitui-se em seis alunos e em dois professores da escola, bolsistas do projeto "Desenvolvimento de uma base de dados da bacia hidrográfica do Rio Negro-RS”, financiado pela FAPERGS.

\section{Resultados}

\section{a) Atividades de divulgaçáo da bacia hidrográfica do Rio Negro-RS}

As atividades de divulgação da bacia hidrográfica do Rio Negro-RS consistiram em: a) confecção de textos informativos sobre a bacia; b)confecção de figuras e mapas; c) realização de palestras; d) realização de cursos de extensão universitária; e) saídas de campo; f) realização de eventos de extensão universitária; g) desenvolvimento de página na internet; h) realização de trabalhos envolvendo geoprocessamento (Sistemas de Informaçóes Geográficas e Sensoriamento Remoto) e i) Estruturação do SIGWeb da bacia hidrográfica do Rio Negro-RS.

Inicialmente, foi realizado um levantamento dos estudos existentes sobre a bacia hidrográfica do Rio Negro-RS e/ou sobre os recursos hídricos existentes em sua área de abrangência. Nesse processo, buscou-se o Departamento de Recursos Hídricos da Secretaria Estadual de Meio Ambiente (DRH/SEMA) e o Comitê de Gerenciamento da Bacia Hidrográfica do Rio Negro-RS (CBRN). A partir daí, os professores envolvidos com o projeto passaram a integrar o CBRN e a participar das reunióes mensais do comitê. Em um primeiro momento, a participaçáo restringia-se às reunióes do comitê, que eram realizadas mensalmente. Em um segundo momento, tendo como base o aumento da compreensão sobre a bacia hidrográfica, obtido a partir da realização de pesquisa bibliográfica, foi possível auxiliar em questóes técnicas.

Desde o ano de 2013, foram realizadas dez palestras sobre recursos hídricos e sobre a bacia hidrográfica do Rio Negro-RS, em escolas, universidades, cursos técnicos e em eventos relacionados ao meio ambiente na área de abrangência da bacia, atingindo aproximadamente 350 pessoas. As palestras foram programadas para terem duraçáo de cinquenta minutos, aproximadamente, sendo voltadas para adultos e jovens, profissionais e estudantes de ensino médio, de nível técnico e universitário. Com públicos tão distintos, a ideia inicial era realizar palestras diferenciadas para cada público alvo. No entanto, optou-se por ministrar apenas um tipode palestra, que poderia ser alterada quando necessário, para atender públicos diferentes.

As primeiras palestras foram requisitadas pelos técnicos do DAEB, em 2013. Em seguida, foram recebidos convites do SENAC, da Prefeitura Municipal de Aceguá, da Prefeitura Municipal de Bagé, da Universidade da Região da Campanha (URCAMP) e do próprio CBRN. Os ouvintes,em geral, eram profissionais e/ou estudantes de nível técnico e superior, servidores ou professores de ensino fundamental e médio dos municípios abrangidos pela bacia hidrográfica. Os autores acreditam que o fato de as 
palestrasversarem sobre a área onde os ouvintes residem, apresentando uma quantidade considerável de mapas, fotografias e figuras tenha contribuindo para a boa aceitação. Os ouvintes expuseram questóes relacionadas aos problemas ambientais vivenciados, às secas, às enchentes, bem como externaram a preocupação com a poluição das águas dos arroios que atravessam as áreas urbanas de Bagé e Hulha Negra e com a quantidade de lixo visível nas suas margens. Muitas vezes, os ouvintes contribuem com dados e/ou informaçóes relevantes para o projeto.

Uma questão importante que pode ser verificada no momento da palestra é a falta de identificação da população com os cursos d'água da região, além do grande desconhecimento de questôes relacionadas aos recursos hídricos e à geografia na área de abrangência da bacia. Em algumas ocasióes, ouviu-se que os arroios que atravessam a área urbana de Bagé eram verdadeiros esgotos a céu aberto e que deveriam ser canalizados. Pouco se falou sobre as possibilidades de despoluição dos rios, revitalizaçáo das margens dos cursos d'água ou sua utilização para fins recreacionais. Grande parte dos ouvintes atribui os problemas relatados à administração pública. Pode-se citar como de grande relevância a constataçáo do desconhecimento, quase que completo, da PNRH e da própria bacia hidrográfica por parte dos integrantes do CBRN.

Ainda com relação ao grau de satisfação com as palestras, foi possível verificar em duas palestras realizadas no município de Aceguá-RS,que grande parte do público era constituídopor estudantes de ensino médio e fundamental eque a estrutura das palestras está inadequada a esse tipo de público. Os ouvintes não demonstraram interesse durante a explanação e também não interagiram ao final da palestra. Dessa maneira, é necessário adaptar o material desenvolvido ou trabalhar de outra maneira, com o auxílio de profissionais capacitados, buscando materiais de divulgaçáo que sejam atraentespara esse público.

Além das palestras, outra atividade em desenvolvimento é a realização periódica de saídas a campo na bacia hidrográfica. Essas saídas têm como objetivo:proporcionar uma visão mais abrangente da área em estudo para a equipe que desenvolve o projeto e permitir que parte da população que reside na bacia tenha a oportunidade de conhecer melhor o local onde vive e tenha contato com os principais problemas relacionados aos recursos hídricos na região. Até o momento, foram realizadas 12 saídas a campo, envolvendo um total de 64 pessoas. Na figura 3, apresenta-se foto da saída de campo realizada no local de encontro entre o Rio Negro e o arroio Piraí, próximo à fronteira do Brasil com o Uruguai, no ano de 2012.

Como o objetivo de fomentar a criação de espaços para a disseminação de informaçóes sobre a bacia do Rio Negro, foram realizados, até o momento, quatro eventos de extensão universitária.

O I Seminário de Pesquisa e Extensão sobre a Bacia Hidrográfica do Rio Negro em território brasileiro buscou reunir docentes universitários e da educação básica, técnicos e discentes, que desenvolviam ou pretendiam desenvolver atividades sobre a bacia hidrográfica do Rio Negro em território brasileiro. O Seminário contou com 14 palestrantes e 90 participantes. $\mathrm{Na}$ ocasiáo, fizeram-se presentes os presidentes dos Comitês de Gerenciamento das Bacias Hidrográficas dos rios Ibicuí e Santa Maria, que proferiram palestras sobre o histórico de atuação de seus comitês. Os dois presidentes ressaltaram a importância da inserção da Unipampa no contexto do desenvolvimento de açóes nas bacias hidrográficas localizadas na região do Pampa gaúcho. 


\section{Figura 3: Saída a campo realizada com residentes na bacia hidrográfica do Rio Negro-RS}

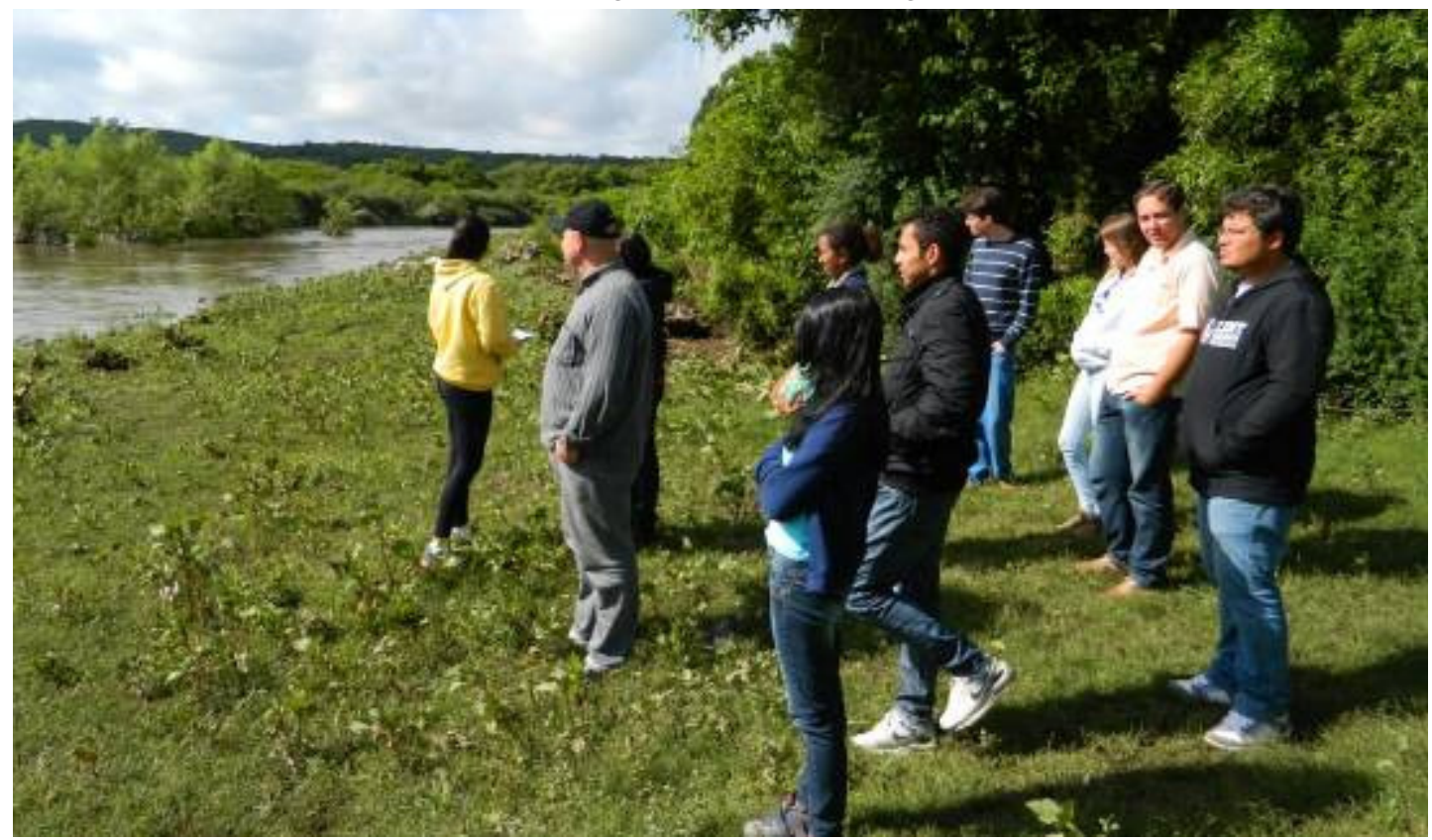

A I e a II Mostra Fotográfica e Cartográfica sobre a bacia hidrográfica do Rio Negro em território brasileiro tiveram como objetivo principal divulgar informaçóes à população local sobre os aspectos físicos e ambientais da bacia hidrográfica, por meio de vídeos, fotografias e material cartográfico produzido por discentes e docentes da UNIPAMPA. $\mathrm{Na}$ figura 4, apresenta-se um registro da II Mostra Fotográfica e Cartográfica.

Em 2015, foi realizada a segunda edição do Seminário de Pesquisa e Extensão Sobre a Bacia Hidrográfica do Rio Negro em Território Brasileiro, juntamente com o Seminário Internacional de Recursos Hídricos, Energia e Desenvolvimento Sustentável. O evento fez parte da agenda oficial do Comitê de Gerenciamento da Bacia Hidrográfica do Rio Negro-RS e contou com a participação da maioria de seus integrantes. Na ocasiáo, foram realizadas onze palestras, uma mesa redonda e dois minicursos, com engenheiros, agrônomos e professorespesquisadores da Universidade Federal de Pelotas (UFPEL), Universidade Federal do Rio Grande do Sul (UFRGS) e da Universidad de la Republica do Uruguay (Udelar). Destaca-se a participação do Secretário Estadual do Departamento de Recursos Hídricos, que ministrou palestra sobre os "Desafios e oportunidades em recursos hídricos na metade sul do Rio Grande do Sul, trazendo novas informações e perspectivas de atuação aos integrantes do CBRN. 


\section{Figura 4: II Mostra Fotográfica e Cartográfica sobre a bacia hidrográfica do Rio Negro em território brasileiro}

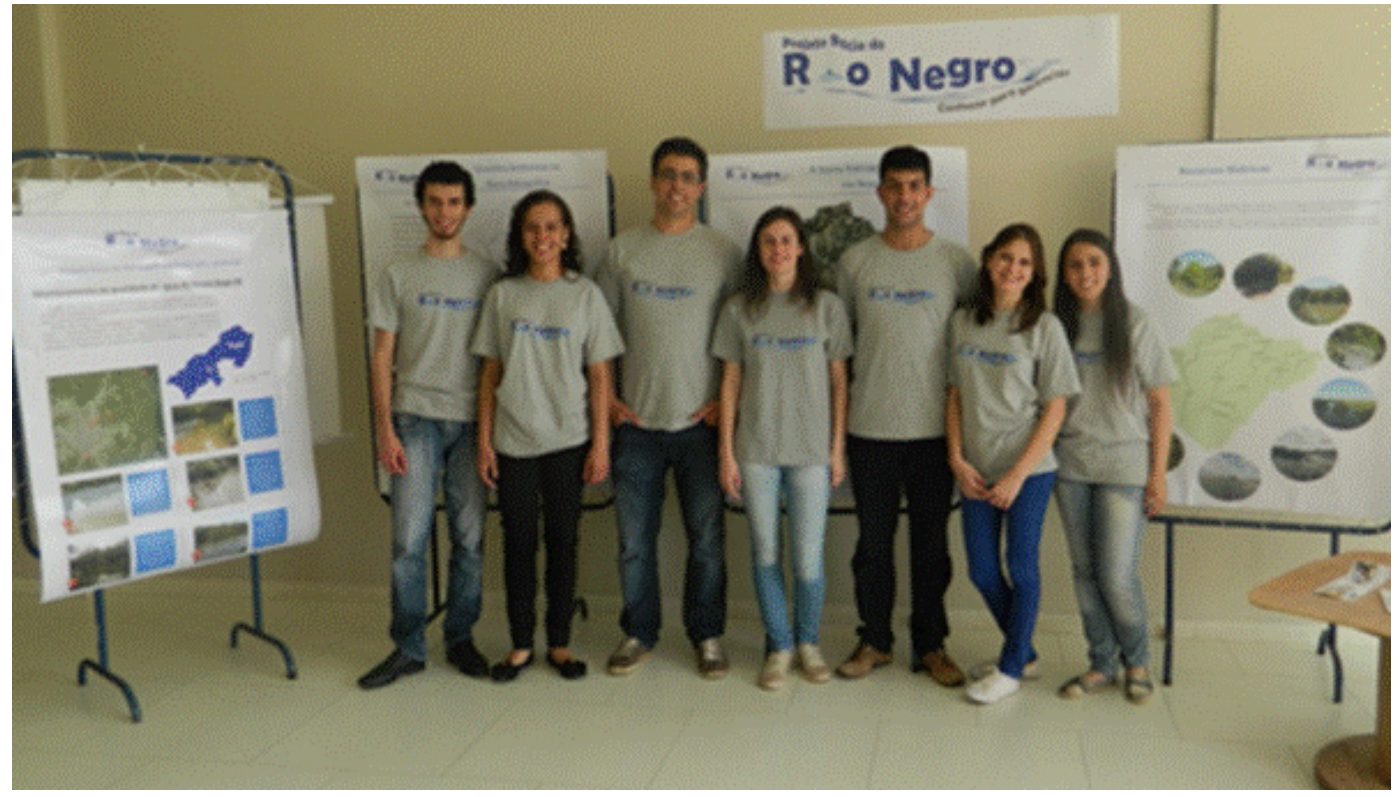

Outras açôes realizadas foram os cursos de extensãouniversitária: a) Introdução à Política Nacional de Recursos Hídricos; b) Introdução ao CAD aplicado ao Geoprocessamento; c) Introdução ao Sensoriamento Remoto e ao Processamento Digital de Imagens; d) Introdução aos Sistemas de Informaçōes Geográficas; e) Introdução ao SIGWeb da Bacia Hidrográfica do Rio Negro-RS.

Foi realizado um conjunto de açóes no campo do geoprocessamento. Essas açóes surgiram a partir da necessidade de organizar parte dos dados geográficos e/ou alfanuméricos encontrados na etapa de pesquisa bibliográfica. Inicialmente, os dados foram estruturados em um banco de dados utilizando programas computacionais de Sistemas de Informaçóes Geográficas (SIG).Em princípio, utilizou-se o programa gvSIG, que é gratuito, e que se mostrou útil para a visualização dos dados espaciais vetoriais armazenados. No entanto, não apresentou a mesma eficiência para a ediçáo de dados, a manipulaçáo dos dados armazenados em formato matricial e a produçáo de mapas. Dessa maneira, optou-se por migrar para o sistema ArcMap, que atendeu satisfatoriamente as demandas existentes. Cabe ressaltar que a opçáo de migrar para o ArcMap se deu a partir de sua aquisição para um projeto de pesquisa da UNIPAMPA. Os dados vetoriais também foram armazenados no SGBD PostgreSQL, utilizando as funcionalidades de sua extensão espacial PostGIS.

Com o desenvolvimento do projeto, surgiu a demanda por verificar as mudanças no uso e cobertura da terra na bacia hidrográfica. De acordo com Munroe e Müller (2007), as mudanças no uso e cobertura da terra sáo resultados da interação entre processos sociais, ecológicos e geofísicos, e tem sido mundialmente reconhecidos, segundo Xiao et al. (2006) e Mendoza et al. (2011), como um dos mais importantes fatores de modificação ambiental. Em ecossistemas de bacias hidrográficas, as mudanças no uso e cobertura da terra influenciam as características do escoamento superficial que, por sua vez, afetam a disponibilidade de água superficial e subterrânea, que leva a outras mudanças no uso e cobertura da terra (SAJIKUMAR e REMYA, 2015). Para verificar as mudanças no uso e 
cobertura da terra, foram utilizadas imagens da série de satélites Landsat. Atabela 1 traz informaçôes sobre as cenas utilizadas no estudo.

\section{Tabela 1: Dados das cenas do satélite Landsat utilizadas no mapeamento do uso e cobertura da terra na bacia hidrográfica do Rio Negro-RS}

\begin{tabular}{|c|c|c|c|c|}
\hline Satélite/ Sensor & Órbita/Ponto & Data & Bandas & $\begin{array}{l}\text { Resolução espa- } \\
\text { cial }(\mathrm{m})\end{array}$ \\
\hline Landsat 2/MSS & $239 / 082$ & $27 / 08 / 1977$ & $4,5,6,7$ & 80 \\
\hline Landsat 5/TM & $\begin{array}{l}222 / 082 \\
223 / 082 \\
\end{array}$ & $\begin{array}{l}04 / 05 / 1985 \\
11 / 05 / 1985\end{array}$ & $1,2,3,4,5,7$ & 30 \\
\hline Landsat 5/TM & $\begin{array}{l}222 / 082 \\
223 / 082 \\
\end{array}$ & $\begin{array}{l}30 / 07 / 1996 \\
05 / 07 / 1996\end{array}$ & $1,2,3,4,5,7$ & 30 \\
\hline Landsat 7/TM & $\begin{array}{l}222 / 082 \\
223 / 082\end{array}$ & $\begin{array}{l}06 / 01 / 2003 \\
29 / 01 / 2003\end{array}$ & $1,2,3,4,5,7$ & 30 \\
\hline Landsat 8/OLI & $\begin{array}{l}222 / 082 \\
223 / 082\end{array}$ & $\begin{array}{l}28 / 11 / 2014 \\
05 / 12 / 2014\end{array}$ & $1,2,3,4,5,6,7,8$ & 15 \\
\hline
\end{tabular}

As imagens foram processadas utilizando técnicas de Processamento Digital de Imagens (PDI) e classificadas utilizando o método da Máxima Verossimilhança (MAxVer), no programa computacional ENVI. Por fim, trabalhou-se na pós-classificação dos mapas de uso e cobertura da terra gerados na classificaçáo supervisionada. Os resultados (tabela 2) indicam que houve significativa alteração nos padróes de paisagem na bacia hidrográfica do Rio Negro-RS.

\section{Tabela 2: Quantificaçáo do uso e cobertura da terra na bacia hidrográfica do rio Negro-RS entre 1977 e 2014}

\begin{tabular}{c|c|c|c|c|c|c|c|c|c|c}
\hline \multirow{2}{*}{ Classe } & \multicolumn{8}{c}{ Quantificação do uso e cobertura da terra } \\
\cline { 2 - 12 } & \multicolumn{2}{|c}{1977} & \multicolumn{2}{c}{1985} & \multicolumn{2}{c}{1996} & \multicolumn{2}{c}{2003} & \multicolumn{2}{c}{2014} \\
\cline { 2 - 11 } & $\mathrm{Km}^{2}$ & $\%$ & $\mathrm{Km}^{2}$ & $\%$ & $\mathrm{Km}^{2}$ & $\%$ & $\mathrm{Km}^{2}$ & $\%$ & $\mathrm{Km}^{2}$ & $\%$ \\
\hline Urbano & 14,96 & 0,45 & 21,26 & 0,71 & 21,04 & 0,71 & 24,98 & 0,83 & 28,13 & 0,92 \\
\hline Florestal & 714,42 & 23,83 & 366,30 & 12,20 & 413,01 & 13,78 & 254,60 & 8,49 & 144,95 & 4,85 \\
\hline Campos & 1975,30 & 65,89 & 2094,80 & 69,88 & 1989,30 & 66,35 & 2017,22 & 67,28 & 1283,80 & 42,00 \\
\hline Água & 33,25 & 1,11 & 68,16 & 2,27 & 59,90 & 1,20 & 71,88 & 2,40 & 91,38 & 3,04 \\
\hline $\begin{array}{c}\text { Cultura tem- } \\
\text { porária }\end{array}$ & 260,70 & 8,69 & 417,01 & 13,91 & 486,12 & 16,12 & 471,36 & 15,72 & 1603,20 & 46,92 \\
\hline Silvicultura & - & - & 31,25 & 1,04 & 29,70 & 0,99 & 158,87 & 5,30 & 47,09 & 1,56 \\
\hline
\end{tabular}

Como se pode verificar na figura 2 , as áreas ocupadas por campos (classe "campestre") e por mata nativa (classe "áreas florestais") tiveram uma considerável redução, enquanto as áreas ocupadas por atividades agrícolas (classe "cultura temporária") aumentaram de 260,70 km² em 1977 para 1603,20 km² em 2014.

Como os dados estavam armazenados em um SIG Desktop, a disponibilização desses dados em um contexto multiusuário tornou-se um problema. Para possibilitar que os usuários acessassem simultaneamente os dados espaciais da bacia hidrográfica do Rio Negro-RS, a solução adotada foi desenvolver uma aplicação SIGWeb. O serviço de mapas foi desenvolvido utilizando o servidor de mapas i3geo, que é gratuito e de 
desenvolvimento nacional. Na figura 5, apresenta-se uma visualizaçáo da tela da aplicaçáo SIGWeb, com os temas "bacia do Rio Negro" e "Recursos Hídricos Principais".

Figura 5: Tela da aplicaçáo SIGWeb da bacia hidrográfica do Rio Negro-RS

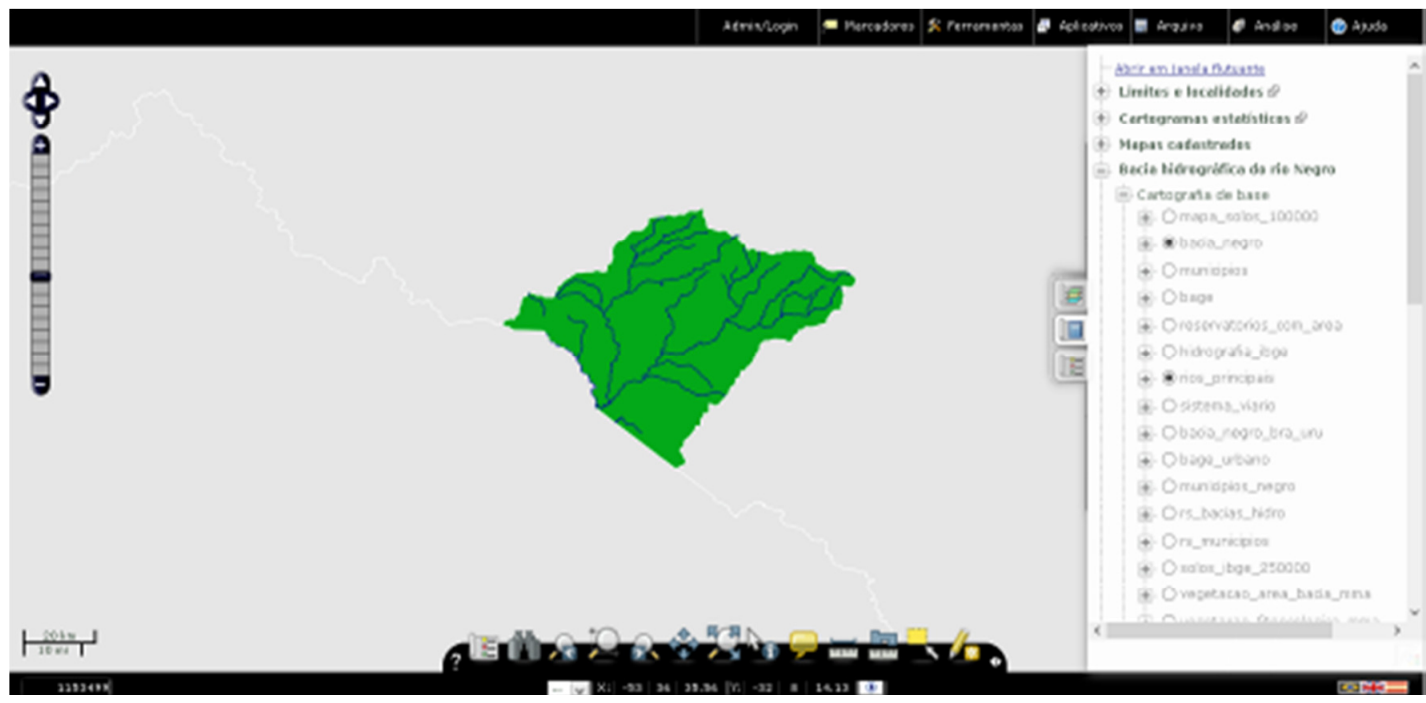

A aplicação SIGWeb desenvolvida vem sendo utilizada apenas pela equipe do projeto de extensão e em projetos de pesquisa sobre a bacia hidrográfica do Rio Negro. Espera-se que, em um futuro próximo, a ferramenta venha a ser utilizada em escolas, prefeituras e outros órgãos públicos.

\section{b) Apoio técnico ao comitê de gerenciamento da bacia hidrográfica do Rio Negro}

O apoio técnico ao CBRN teve início a partir da percepçáo da potencialidade da equipe do projeto de extensão em auxiliar na resoluçáo de alguns problemas enfrentados pelo comitê. Conforme colocado anteriormente, a participaçáa dos professores,inicialmente, restringia-se às reuniôes mensais do comitê. Em um segundo momento, tendo como base o aumento da compreensão sobre a bacia hidrográfica, foi possível auxiliar ao CBRN.Até o momento, as atividades desenvolvidas no âmbito do CNRN foram: a) Organização de dados e confecção de material cartográfico para auxiliar nas reuniốes do CBRN; b) Realizaçáo de palestras; c) Participaçáo na diretoria do comitê; d) Participação na Comissão Permanente de Assessoramento (CPA) do CBRN; e) Realização de palestras; f) Confecção de plano de trabalho do CBRN.Na figura 6, apresenta-se o registro de uma das reunióes do CBRN, realizada em abril de 2015, na Associação Rural de Bagé. 


\section{Figura 6: Registro de reuniáo do CBRN}

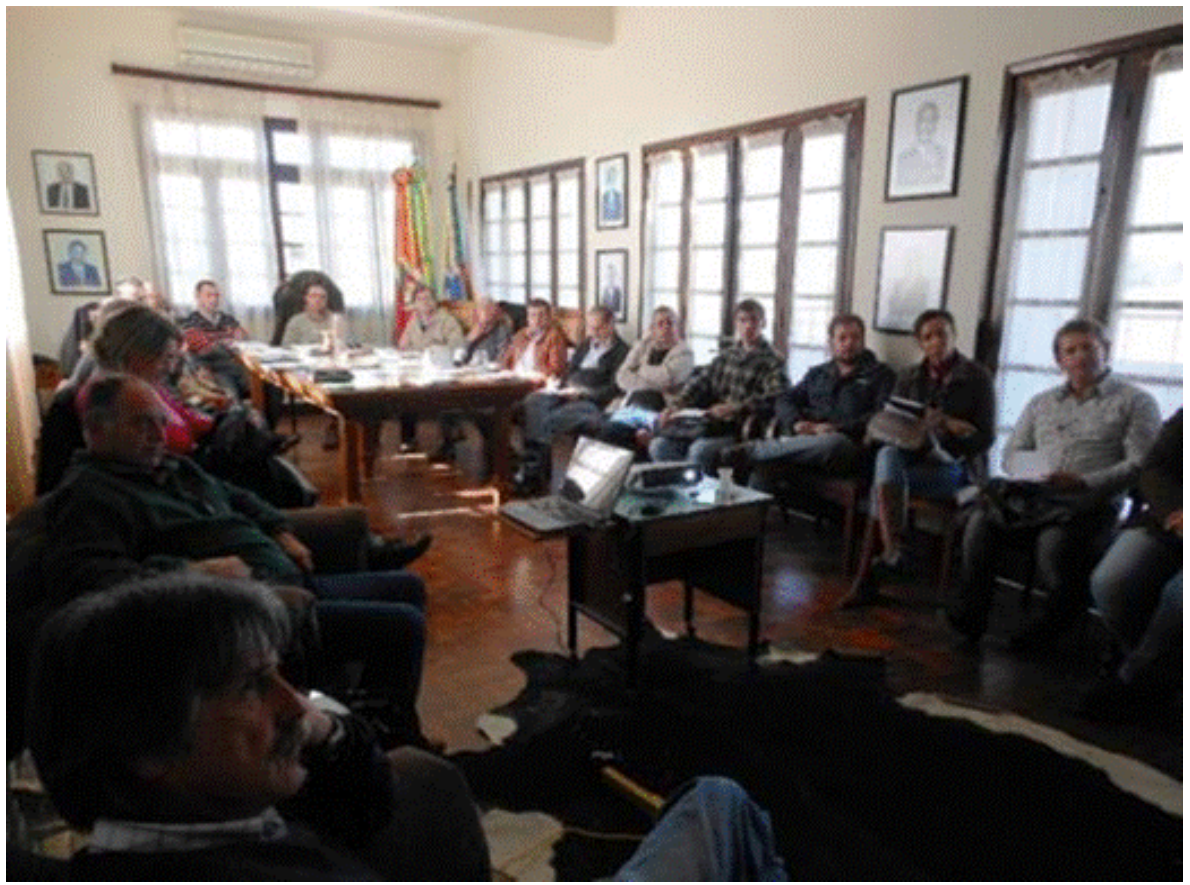

\section{c) Atividades no Colégio Estadual de Ensino Médio Dr. Carlos Kluwe}

No ano de 2014, foi aprovado um projeto de pesquisa intitulado "Desenvolvimento de uma base de dados da bacia hidrográfica do Rio Negro-RS", no edital FAPERGS/ PICMEL. O edital previa bolsas para dois professores e para seis alunos de escolas públicas de ensino médio. A escola parceira na realizaçãodo projeto foi o Colégio Estadual de Ensino Médio Dr. Carlos Kluwe, localizadono município de Bagé-RS. Os professores tinham formação em Geografia e em Engenharia Química.

Os alunos bolsistas estavam entre o primeiro e o segundo ano do ensino médio. Para a realizaçáo do projeto de pesquisa, era necessário que os alunos tivessem conhecimentos teóricos e práticos sobre Geoprocessamento, além de conhecimentos teóricos sobre a PNRH. Para suprir essa demanda, organizaram e ministraram cinco cursos de extensão universitária introdutórios, voltados para os alunos e professores bolsistas, com algumas vagas destinadas ao público em geral.

No decorrer dos cursos, foram realizadas saídas a campo, com o objetivo de proporcionar uma visáo sobre a bacia hidrográfica do Rio Negro-RS, no contexto da PNRH e do Geoprocessamento.

A partir da realização dos cursos, foi possível verificar que a formação em geoprocessamento era uma demanda não só referente ao projeto de extensão, como também de determinados setores de órgãos públicos dos munícipios abrangidos pela bacia, que demandaram vagas nos cursos.

Após a realização dos cursos, os alunos foram divididos em dois grupos. Um grupo desenvolveu atividades na área de sensoriamento remoto, enquanto o outro grupo desenvolveu atividades relacionadas com SIG.

A figura 8apresenta no mapa de uso e cobertura da terra da bacia hidrográfica do Rio Negro, em dezembro de 2014, elaborado com o auxílio dos alunos bolsistas de ensino médio. 
Figura 8: mapa de uso e cobertura da terra na bacia hidrográfica do Rio Negro-RS em 2014

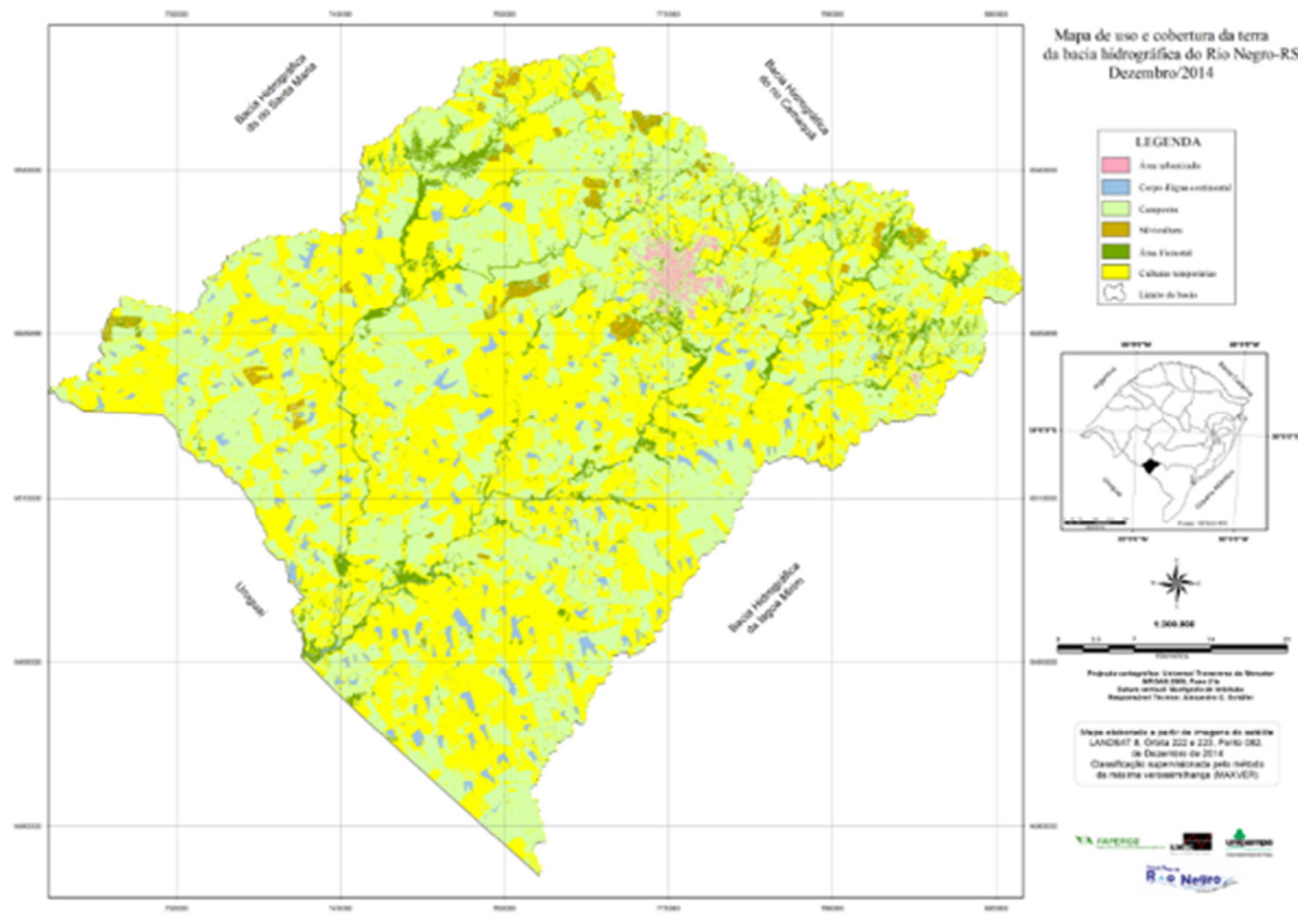

Em maio de 2015, foi realizado um seminário no auditório do Colégio Carlos Kluwe. Os alunos bolsistas apresentaram para os demais alunos da escola o trabalho que estavam desenvolvendo, bem como os primeiros resultados alcançados. Na ocasiáo, aproximadamente cem alunos do ColégioEstadual Carlos Kluwe participam do seminário. Nas figuras 9 e 10, têm-se registro da apresentaçáo de alunos bolsistas do projeto (figura 9)e do público presente (figura 10) no seminário.

Figura 9: Discentes do Colégio Estadual Dr. Carlos Kluwe apresentando um relato das atividades em desenvolvimento

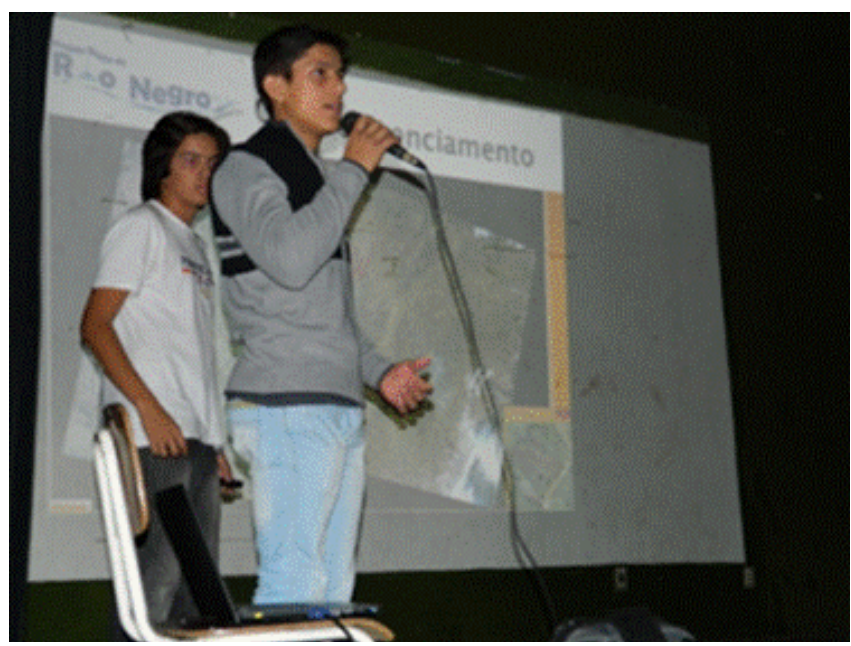




\section{Figura 10: Registro do público presente no seminário realizado no ColégioEstadual de Ensino Médio Dr. Carlos Kluwe}

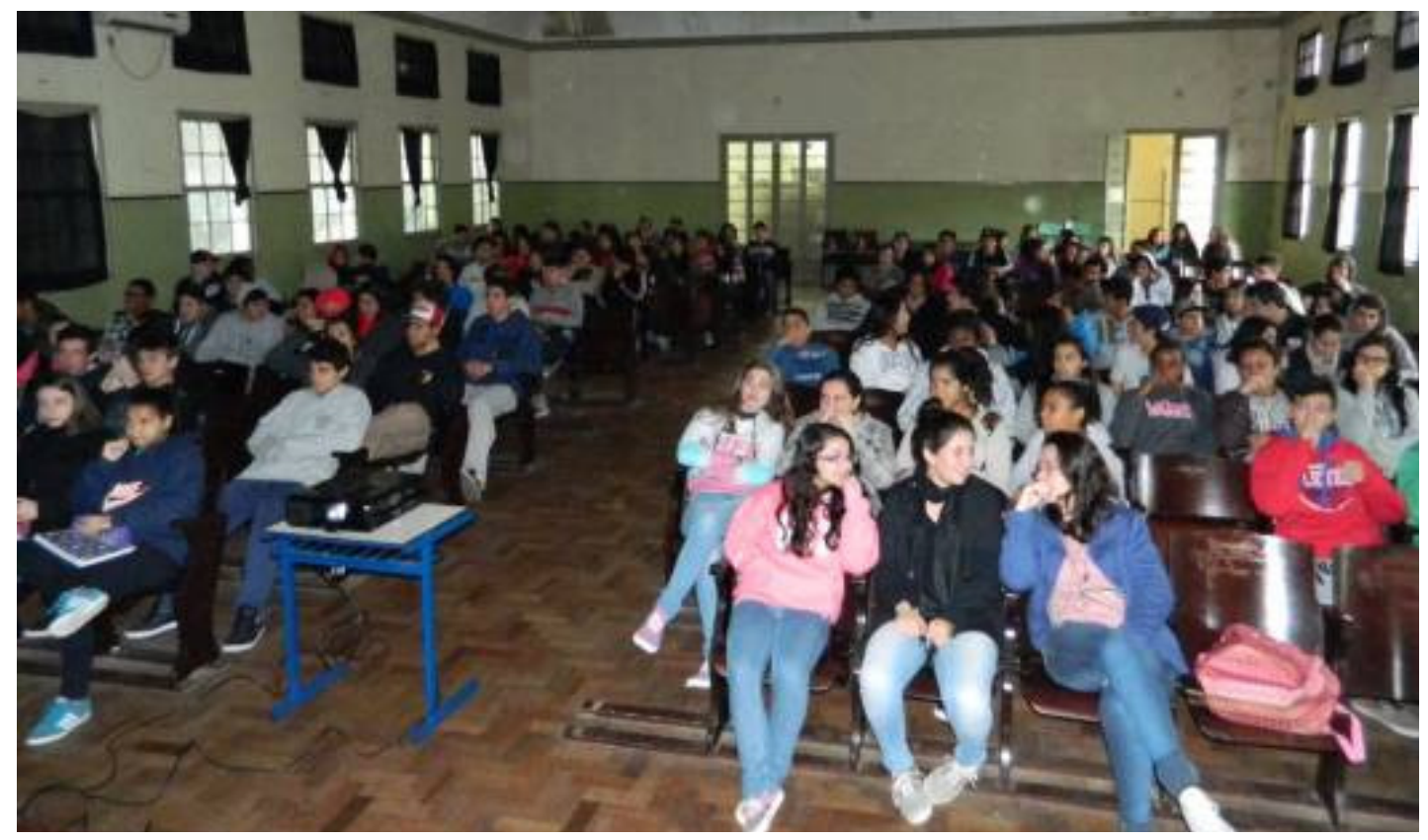

Em outubro de 2015, foi realizado na UNIPAMPA o seminário de encerramento do projeto de pesquisa do edital PICMEL/FAPERGS, paralelamente ao seminário trimestral do Laboratório de Modelagem, Simulação Computacional e Geoprocessamento (LMSCGeo) da UNIPAMPA. Também foi realizado um balanço das atividades desenvolvidas ao longo do projeto, no edital PICMEL, em que alunos e professores expuseram as principais dificuldades e desafios encontrados ao longo do projeto, bem como a experiência adquirida.

Dois dos alunos participantes do projeto PICMEL são, atualmente, bolsistas do programa de bolsas de ensino médio no CNPQ e estâo dando continuidade ao projeto de pesquisa submetido ao edital PICMEL/FAPERGS.

\section{Consideraçóes Finais}

As açóes desenvolvidas vêm contribuindo para o aumento do conhecimento sobre os aspectos físicos e ambientais da bacia do Rio Negro-RS; epara fomentar o contato da universidade com o poder público, com a comunidade e com os $\mathrm{CBHs}$ (Comitês de Bacias Hidrográficas), tanto da bacia do Rio Negro quanto de outras bacias hidrográficas que apresentam características e desafios comuns.

No decorrer da execuçáo do projeto, professores, técnicos e discentes foram se agregando à equipe inicial. Até o momento, 21 alunos dos cursos de graduaçáo em Engenharia de Produção, Engenharia da Computação, Engenharia Química e Engenharia de Energias Renováveis e Ambiente participaram das atividades do projeto. Os alunos desenvolveram atividades relacionadas à extensáo universitária, à pesquisa e ao ensino. Essas atividades resultaram em 10 artigos completos, 14 resumos expandidos e mais de 20 resumos publicados em eventos no Brasil e no exterior. Atualmente, a equipe é constituída 
por três professores, além de nove alunos (bolsistas e voluntários) dos cursos de Engenharia daComputação, Engenharia de Energias Renováveis e Ambiente, Engenharia Química e Engenharia de Produção, campus Bagé, e de um aluno do curso de Engenharia Sanitária e Ambiental do campus Caçapava do Sul, da UNIPAMPA.

Após três anos de execução do projeto de extensão, é possível afirmar que se está contribuindo para a conscientizaçáo da população que habita a bacia hidrográfica do Rio Negro sobre sua importância no contexto local e internacional, bem como a respeito da preservaçáo dos recursos hídricos localizados no interior da bacia hidrográfica. No entanto, tem-se consciência de que o trabalho realizado até o momento se constitui em uma pequena contribuição no contexto do conhecimento e divulgação dos aspectos físicos, econômicos e sociais na área de abrangência da bacia hidrográfica do Rio Negro em território brasileiro.

Por fim, ressalta-se que embora se tenha apresentado neste artigo uma série de experiências exitosas, é importante deixar claro que diversas açóes não tiveram os resultados esperados e/ou planejados. No entanto, os erros e os problemas enfrentados ao longo do desenvolvimento do projeto não foram encarados como fracassos. Ao contrário, vêm servindo como um grande aprendizado e motivação neste processo de "aprender fazendo", parte do desenvolvimento deste projeto.

\section{Referências}

ANA - AGÊNCIA NACIONAL DE ÁGUAS. Conjuntura dos recursos hídricos no Brasil: Informe 2014. Brasília, 2015.

ANA - AGÊNCIA NACIONAL DE ÁGUAS. Arquivos digitais do Sistema de Informações Hidrológicas HidroWeb. Disponível em: http://hidroweb.ana.gov.br/HidroWeb. asp?Tocltem=4100. Acesso em 05/03/2015.

BRASIL. Lei no 9.433, de 8 de janeiro de 1997. Brasília, 1997.

DAEB - DEPARTAMENTO DE ÁGUA E ESGOTO DE BAGÉ- Caracterização e diagnóstico da bacia do Rio Negro em Território Brasileiro-RS. Contrato nº04/2007. Bagé, 2007.

GOOGLE. Google Earth Pro. Version 7.1.5.1557. 2016. Área de abrangência da bacia hidrográfica do Rio Negro-RS. Disponível em: https://www.google.com.br/earth/ download/ge/agree.html. Acesso em: 15/07/2015.

Hasenack, H.; Weber, E.(org.) Base cartográfica vetorial contínua do Rio Grande do Sul - escala 1:50.000. Porto Alegre: UFRGS Centro de Ecologia. 2010. 1 DVD-ROM. (Série Geoprocessamento n.3). ISBN 978-85-63483-00-5 (livreto) e ISBN 978-85-63843-01-2 (DVD).

IBGE. Censo Demográfico 2010 - Resultados do universo. Disponível em: http://www.ibge. gov.br. Acesso em: 20 out. 2013.

IHP-HWRP.GLOWA: Global change and the hydrological cycle. Germany Federal Ministry of Education and Research.Koblenz, 2008. 
MENDOZA, M., LÓPES-GRANADOS, E., GENELETTI, D. PÉREZ-SALICRUP, D., SALINAS, V.Analysing land cover and land use change processes at watershed level: A multitemporal study in the Lake Cuitzeo Watershed, Mexico (1975-2003). Applied Geography, 31, 237-250, 2011.

MUNROE D., MÜLLER D. Issues in spatially explicit statistical land-use/cover change (LUCC) models: Examples from western Honduras and the Central Highlands of Vietnam. Land Use Policy, 24, 521-530, 2007.

RAVANELLO, M. M.; PANTE, A. R. Outorga de direito de uso de recursos hídricos em bacia carente de dados - Rio Negro-RS. Anais do XX Simpósio Brasileiro de Recursos Hídricos. Bento Gonçalves, 2013.

RIO GRANDE DO SUL. Decreto n 45.531, de 5 de março de 2008. Porto Alegre, 2008.

SAJIKUMAR,N., REMYA, R. Impact of land cover and land use change on runoff characteristics. Journalof Environmental Management, 161, 460-468, 2015.

SEMA- SECRETARIA ESTADUAL DE MEIO AMBIENTE. Relatório Anual sobre a Situação dos Recursos Hídricos no Estado do Rio Grande do Sul. Porto Alegre: SEMA, 2006.

SEMA- SECRETARIA ESTADUAL DE MEIO AMBIENTE. Relatório Anual sobre a Situação dos Recursos Hídricos no Estado do Rio Grande do Sul. Porto Alegre: SEMA, 2012.

SEMA- SECRETARIA ESTADUAL DE MEIO AMBIENTE. Limites das bacias hidrográficas do Rio Grande do Sul. Disponível em http://www.sema.rs.gov.br/conteudo.asp?cod_menu=21\&cod_conteudo=6463. Acessoem 05/03/2015.

UNESCO.The United Nations World Water Development Report 2003: Water for People Water for Life. UNESCO,França, 2003.

UNESCO.The United Nations World Water Development Report 2015: Water for a Sustainable World. UNESCO,França, 2015.

XIAO, J., SHEN, Y., GE, J., TATEISHI, R., TANG, C., LIANG, Y. et al.. Evaluating urban expansion and land use change in Shijiazhuang, China, by using GIS and remote sensing. LandscapeandUrban Planning, 75 $(1 / 2), 69-80,2006$. 